\title{
The Role of Regulations and Ethics Auditing to Cope with Information Technology Governance from Point View Internal Auditors
}

\author{
Atallah Ahmad Al Hosban ${ }^{1}$ \\ ${ }^{1}$ Irbid National University, Jordan \\ Correspondence: Atallah Ahmad Al Hosban, Irbid National University, Jordan. E-mail: aalhosban@gmail.com
}

Received: September 9, 2014

Accepted: October 21, 2014

Online Published: December 25, 2014

doi:10.5539/ijef.v7n1p167

URL: http://dx.doi.org/10.5539/ijef.v7n1p167

\begin{abstract}
This study aimed to identify the requirements of the IT internal audit from the standpoint of corporate governance in terms of the regulations, instructions and ethics with the addition of the idea of the existence of internal auditing offices. Questionnaire was used as a tool to get the information was distributed to the internal auditors in the Jordanian commercial banks have been using the system for Likert, hypotheses were tested using sample t-test with the acceptance of these alternative hypotheses and reject hypotheses nihilism.

The most important results of this study: that the regulations and the company adapted to the social conditions to ensure good implementation by her staff, and assess the degree to submit to the rules and regulations and amendments thereto staff and especially the financial and accounting by the internal auditor, and help offices internal audit of the external auditor to give professional opinion more clearly and independently, and the presence of activating the role of the government through the availability of qualified professionals in the process of issuing laws and language understandable in conjunction with non-state actors and the relevant accounting and auditing.

The most important recommendations of the study: the application of international standards on ethics functional audit such as: integration, objectivity, and independence, and mutual trust, and the holding of specialized conferences to sensitize stakeholders to promote the concept of corporate governance and their impact on the vision and mission of the banks, and that is reviewed laws and regulations from time to time in order to ensure them and their suitability for business and new companies out of business and activities through various technological developments, both internally and externally effects.
\end{abstract}

Keywords: regulations, ethics, internal auditor, IT gevernance

\section{Introduction}

The scope of internal auditing within an organization is broad and may involve topics such as an organization's governance, risk management and management controls over: efficiency/effectiveness of operations (including safeguarding of assets), the reliability of financial and management reporting, and compliance with laws and regulations. Internal auditing may also involve conducting proactive fraud audits to identify potentially fraudulent acts; participating in fraud investigations under the direction of fraud investigation professionals, and conducting post investigation fraud audits to identify control breakdowns and establish financial loss.

Governance was first posited to be an agency problem, that is, one where power between the owners of a corporation (shareholders) was less than that of its managers who, though not owners, had near-perfect information about the company and its operations. Owners and managers also sometimes had conflicting goals: owners for wealth-maximization, managers for ongoing employment with high remuneration. "Agency loss", then, occurred when managers pursued objectives that were more in their interest than in the interests of the many, typically diffused shareholders Principals were aware of these possible agency losses, and took steps to minimize them by imposing contracts and performance checks on management, mainly through elected representatives, some from outside the organization, that formed a Board of Directors, and hence, corporate governance. Directors, in turn, organized themselves to provide appropriate levels of scrutiny towards the organization, mainly through Audit and Compensation committees composed solely of external (independent) directors. 


\subsection{Problem Study}

1)-How does the internal auditor deals with instructions on information technology governance environment?

2)-How does the internal auditor deals with ethics audit in the environment of the information technology governance?

\subsection{The Study Hypotheses}

1)-Internal auditor does not deal in insurance companies with regulations and instructions on information technology governance environment.

2)-The auditor does not deal in insurance companies requirements ethics audit in the environment of the information technology governance.

\subsection{Importance of Study}

With respect to IT governance, this study argues the need to promote ethical compliance in order for firms to achieve their IT governance effectively. Such an environment is useful in preventing and detecting conduct that may endanger the objectives of IT governance, and in particular, alignment of business and IT aims. Accordingly, this factor is significant in achieving the wealth creating perspectives of effective IT governance for the organization. The importance of IT to business functions is well documented IT, for so long having been considered an enabler of an organizations strategy, is now viewed as an integral part of an organizations strategy in facilitating the exploitation of information-based competitive advantage to maximize benefits, capitalize on opportunities, and promote organizational growth. In this regard, IT has progressed from being a separate function marginalized from the rest of the organization to increasingly critical. In many organizations, audit committees and management have differing expectations of internal audit. An optimized internal audit function can provide a balance between protecting and enhancing enterprise value by taking a holistic approach to risk management across the enterprise and providing independent and objective assurance with value-added advice.

\subsection{Objectives of Study}

The objectives of the study were as follows:

1)-To assess the adequacy of IT governance structure from the point view for internal auditor.

2)-To assess the degree of alignment and integration between internal auditors and auditing ethics.

\subsection{Previous Studies}

1)-Study of Green (2009). The role of a culture of compliance in information technology governance.

"Ethics has been perceived as one of the most important factors in establishing good corporate governance. Information Technology (IT) plays an increasing role in helping modern organizations to achieve their goals, and it has become critical in creating and implementing effective IT governance mechanisms. This study examines the extent to which an ethic or culture of compliance in IT within an organization influences the overall effectiveness of IT governance, and the factors that contribute to this effect. Responses from 122 internal auditors, members of ISACA (Information Systems and Audit Control Association) Australia, show that two factors contributed to the ethics or culture of compliance in IT: corporate communication systems and the involvement of senior management in IT. This study advances our understanding of the roles of IT governance mechanisms and their impact on the overall effectiveness of IT governance. Furthermore, the findings of this study provide empirical results on the IT governance mechanisms that have been previously studied mainly by normative and case study approaches."

2)-Study Al-Hosban (2014) Impact of conditional factors on internal control system in keeping with the requirements of information technology from the point of view of ICT auditors at commercial banks in Jordan.

This study aims to Identify the linking of police supervision of the internal control system and identify the impact of these link in promoting the concept of banking supervision, and highlight the concept of conditional and control areas of evolution and their use. this study depends up on deductive approach: through the questionnaire user-friendly design and characteristics of the study include the study variables and assumptions. the most finding of this study: An Auditors provide management about the reliability of it systems and how to control environmental factors both internal factors or external factors and internal oversight helps to identify opportunities and threats of the external environment and identify the strengths and weaknesses of the internal environment factors, An Auditor shall determine the conditions of uncertainty in the information technology environment which reduces risks of modern technology and investment opportunities by internal oversight, and Auditors should focus on expanding the information and try to adjust its deployment in large organizations 
because it will have a wide range of information about internal activities. and main recommendation are: The auditor training and education programmers on information security risks and their impact on the company's working environment. The role of internal audit and the internal control system in determining a company's information technology tools, audit, and determine the costs for those programs, and Conferences, seminars, known researcher conditional control factors on large business organizations particularly banks.

3)-Study of IIA (2012). Global technology audit guide (GTAG®) 17 auditing IT governance.

As defined by The Institute of Internal Auditors' (IIA's) International Professional Practices Framework (IPPF), governance is "the combination of processes and structures implemented by the board1 to inform, direct, manage, and monitor the activities of the organization toward the achievement of its objectives." The internal audit activity is uniquely positioned and staffed within an organization to make significant contributions toward achievement of these objectives by providing assurance and consulting services related to organizational governance. While effort is generally focused on the delivery of governance services, the IT component, in many cases, continues to be lacking or ignored. Combined with the continued increase in the speed of technological advancement, IT proliferation, and organizational dependence on IT, it is clear why the internal audit activity should address this inherently high risk area. To this end, an interpretation of IIA Standard 2110: Governance states, "the internal audit activity must assess whether the information technology governance of the organization supports the organization's strategies and objectives."

4)-Study of mohair 2010. Auditing IT governance.

Effective IT governance helps ensure that IT supports business goals, optimizes business investment in IT, and appropriately manages IT-related risks and opportunities. Organizations that realize the IT is no longer a support process and embeds value and risks need a structured approach for better managing Information Technology, enable its capability to deliver added value enterprise wide and for setting up a risk management program to address new risks arising for usage of IT in business processes. In order to assess if IT Governance is in line with industry practices, IT Auditors need a good understanding of processes and applicable standards, particular audit work programs and experience in assessing potential problem indicators.

\subsection{Differentiate This Study from above Studies}

1)-This study concentrate on commercial banks which depend up on new technologies to obtain competitive advantages.

2)-This study depend up on internal auditors who must compliance in regulation and ethics of audit function.

3)-This study practical to defined level of application for regulation and ethics by internal auditors in commercial banks.

\section{Methodology of the Study}

The researcher adopted a descriptive analytical study ends, this section deals with the methodology adopted by the study in detail through the following aspects:

\subsection{First: Data Collection Methods}

In this study rely on two sources of data collection:

1)-Secondary sources: By reference to Arabic and foreign books, journals, articles, periodicals, as well as the studies, and field research, which was in Jordanian society, and specialized scientific conferences and various sites on the Internet for theoretical study.

2)-Primary sources: Have been collected through the questionnaire prepared by the previous studies and research, to choose the premises, CFO, addressed to the heads of (cost accounting and management accounting and control, internal audit, accountants in the workplace).

\subsection{Second: Society and the Study Sample}

Society consist of internal auditors in commercial banks which registered in Amman security exchange, and sample of study commercial banks in primary markets.

\section{Theoretical Framework of Study}

An IT Governance audit evaluates an IT organization's strategic and operational alignment with its enterprise's business strategy, ensuring that IT is supporting the organization's overall goals while measuring IT delivery performance and transparently reporting the results. This type of audit will assess how an IT organization is functioning overall, what key metrics management needs and what value it provides to the enterprise. According 
to the IT Governance Institute, there are five focus areas: Strategic alignment: Linking business and IT so they work well together, Value delivery: Making sure that the IT department does what's necessary to deliver the benefits promised at the beginning of a project or investment., Resource management: Ensuring that resources are managed effectively and efficiently, Risk management: Establishing a formal risk framework that puts some rigor around how IT measures, accepts, manages and reports risk approach, and Performance measures: Putting structure around both qualitatively and quantitatively measuring IT performance (Information Systems Audit and Control Association, IS Auditing Guideline, Use of Risk Assessment in Audit Planning 2009).

Auditing IT Governance needs more business knowledge than regular Information Systems (IS) audits because the IS auditor has to evaluate how IT is enabling the business strategy. IT is not longer seen as support process, but because a project is not enough to respond itself to a business outcome, multiple projects should managed together as programs. This makes a brief presentation of IT Governance practices, the Val IT Framework and the IS Auditor Process in order to explain the approach and the purpose of the Audit Work Program.

The purpose of IT governance is to direct IT endeavors, to ensure that IT's performance meets the following objectives: Alignment of IT with the enterprise and realization of the promised benefits, Use of IT to enable the enterprise by exploiting opportunities and maximizing benefits, Responsible use of IT resources, and Appropriate management of IT-related risks (IT Governance Institute, Board Briefing on IT Governance, pp. 1114).

In the current business climate where a tremendous amount of importance is being given to governance, risk, and compliance (GRC), the concept of IT governance is becoming an increasingly strong component. Executive's Guide to IT Governance explains IT governance, why it is important to general, financial, and IT managers, along with tips for creating a strong governance, risk, and compliance IT systems process. Practical, no-nonsense framework for identifying, planning, delivering, and supporting IT services to your business, Helps you identify current strengths and weaknesses of your enterprise IT governance processes Explores how to introduce effective IT governance principles with other enterprise GRC initiatives (Robert, 2013).

Management should understand the importance of managing the IT enabled investments as programs, as business benefits might not be tracked at project level. Organizational change has to be involved to see IT investments from a business value perspective, and business case development should be supported by standard modeling, and Management should seek to optimize the performance of the portfolio, establishing successful trends in line with strategy. Organization should be able to incorporate any external or internal changes of business environment into the investment portfolio, to manage the performance and adjust it based on new requirements (Information Systems Audit and Control As-sociation, CISA Review Manual, 2009).

IT governance involves managing IT operations and IT projects to ensure alignment between these activities and the needs of the organization defined in the strategic plan. Proper alignment between IT and the organization means: 1) organization management understands the potential and limitations of IT; 2) the IT function understands the objectives and corresponding needs of the organization; and 3) this understanding is applied and monitored throughout the organization via an appropriate governance structure and accountability. Understanding the value and the cost of IT is important for the board and senior and IT management. Successful alignment between the organization and IT occurs when goals and objectives of the organization are aligned with the needs of the organization, and IT is able to meet those needs in collaboration with management (IIA, IT Governance) ethics in establishing good corporate governance. Effective ethical compliance management has several advantages. First, as employees ethical and legal awareness increase, the employees tend to ask questions correctly and, in the end, do "the right thing" when facing dilemmas. Second, it influences employees to be willing to report violations to management, thus contributing to process transparency in the organization. Finally, it increases employees' commitment, because a culture of ethical compliance creates value congruence that generates a sense of community and organizational commitment among employees (Trevino et al., 1999; Trevino, Weaver, Gibson \& Toffler, 1999).

It is important for top management to lead in promoting awareness of ethical compliance within their organization, as it sends messages to employees that inevitably shape the culture of their organizations. The involvement of senior management sends messages that "bond" or help to align employees actions to the goals of the organization, and thus it contributes to wealth creating perspectives of governance. argue that the organizations leaders play critical roles in communicating and demonstrating the importance of ethical values to the organization stakeholders (Meyer, 2004).

With respect to IT governance, argues the need to promote a culture of ethical compliance in order for firms to achieve their IT governance effectively. Such an environment is useful in preventing and detecting conduct that 
may endanger the objectives of IT governance, and in particular, alignment of business and IT aims. Accordingly, this factor is significant in achieving the wealth creating perspectives of effective IT governance for the organization (Parent \& Reich, 2009).

Implicit in most governance legislation and regulation is the need for prudent governance of organizations IT functions. A companies spend as much on information technology each year as they do on offices, warehouses and factories combined. As a result of these large investments, the consequences of any disasters are likely to be profound and lasting (Coffin, 2003).

The application of the framework is a prerequisite to conducting assurance work. The standards are mandatory while guidelines, tools and techniques are designed to provide non-mandatory assistance in performing assurance work and additional detail to support compliance with standards (ISACA, 2011).

Governance, Regulatory and Compliance continues to be complex business challenge. As new laws and regulations are introduced to auditors to keep with their requirements challenge boards to greater levels of transparency, objectivity and professionalism. Increased accountability and potential exposure to liability means directors need to ensure that corporate governance standards are adhered to and robust compliance management systems are in place (Farrell, 2014).

So that, Legal \& Regulatory Compliance is about Ensuring that your staff, policies and procedures are compliant with legal and regulatory requirements and industry best practice. It's the duty of senior managers who have the responsibility and accountability for risks, in particular, the task of managing information risk does not fall solely to IT managers. Our team carries out a compliance audit of your organization IT infrastructure, policies and procedures, which will provide you with a comprehensive, and impartial, assessment of how well your organization meets each of its legislative compliance obligations. We'll also provide you with a Structured Improvement Plan detailing the corrective actions you'll need to take to achieve compliance, we assist you ensure that corrective efforts and resources are focused on the most appropriate areas of your business, and IT technology is key to supporting your business processes. We will review the policies, procedures and activities that contribute to your controls. These can include infrastructure configuration, change and patch management.

Information technology (IT) auditors within internal audit departments are in a position to add great value to their organizations. Many IT auditors have found that continuous auditing (CA) and continuous monitoring $(\mathrm{CM})$ provide effective control assessments at very low marginal cost. Managers have also quickly recognized the value added by CA and CM. However, a common unrecognized ethical dilemma exists when an IT auditor provides both CA and CM: the potential for losing long-term auditor independence and objectivity because of the different purposes each service has within an organization, The main point of all accountancy and auditorrelated codes of ethics is that key ethical principles must be considered carefully when seeking to make sound professional judgments. Just because no laws are broken or no promulgated rules are violated, does not mean that the most ethically correct behavior is being exhibited. The professional responsibility of an auditor is to consider the ethical principles - the spirit of the rules - that require long-term consideration of the organization and the audit profession, as well as the immediate stakeholders (Jill, 2014).

Independence and objectivity are emphasized so strongly because when these principles are impaired, so too is the value of an audit. If the user of an audit report does not believe that the auditor is independent and objective, the reliability of information in the audit report is questioned. Therefore, all professional auditors need to be independent in both fact and appearance. ISACA, the Institute of Internal Auditors (IIA) and International Ethics Standards Board for Accountants (IESBA) codes extend the concept further by requiring organizational independence for the internal audit department as well as that of each auditor (De Prada, 2002).

Auditors provides a comprehensive view on sustainability information and financial reporting, including disclosures relating to going concern, sources of income, positive and negative impacts of the company's operations including future remediation. The Audit Committee together with the SETS board committee has oversight over sustainability and reporting thereof. The Audit Committee assists the board by reviewing the reliability of information included in the integrated report and making sure that there are no conflicts with the financial information reported. The Audi Committee oversees the provision of assurance over sustainability issues (Harshbarger \& Holden, 2004).

The corporate governance structure specifies the distribution of rights and responsibilities among different participants in the corporation, such as, the board, managers, shareholders and other stakeholders and spells out the rules and procedures for making decisions in corporate affairs. By doing this, it also provides the structure through which the company objectives are set and the means of attaining those objectives and monitoring performance (Jacobs, 2004), observes that despite certain congruities and convergences, there are some very 
important differences in the character and content of ethical and legal requirements which can help us understand why ethics is accorded a normative primacy in practical affairs and legality is to be judged by reference to ethics (not vice versa).Specifically, law is concerned primarily with conduct and ethical requirements are centrally concerned with reasons, motives, intentions, and more generally with the character that expresses itself in conduct (Arjoon \& Gopaul, 2003).

Auditors determines the effectiveness of IT governance mechanisms, revealing that the existence of three mechanisms-an IT steering committee, the involvement of senior management in IT, and corporate performance measurement systems-were positively correlated with the effectiveness of IT governance. Two additional mechanisms (centralization of IT decision-making and the position of the IT function within the organization) were not supported (Vaswani, 2003).

The importance of IT to business functions is well documented IT, for so long having been considered an enabler of an organizations strategy, is now viewed as an integral part of an organizations strategy in facilitating the exploitation of information-based competitive advantage to maximize benefits, capitalize on opportunities, and promote organizational growth. In this regard, IT has progressed from being a separate function marginalized from the rest of the organization to increasingly critical (El Sawy, Omar, \& Pavlou, 2008).

The audit committee may also assist the board in monitoring compliance with laws and regulations. In addition to reviewing reports from regulators about company compliance, the audit committee should meet periodically with compliance officers and the general counsel to better understand the company's compliance process. Now more than ever, the public focuses on the reputation of a business. Consequently, companies should adopt and adhere to a formal code of ethics. The code of ethics can help establish a culture among employees where ethical behavior thrives, helping deter fraud. While the audit committee is not responsible for determining ethical standards, it is often consulted when a company is developing or challenging its code of ethics (Haes \& Grembergen, 2004).

The following four rules will help businesses to start thinking about the major issues challenge auditors in IT Governance (Guldentops, 2007).

1). IT governance is about effectiveness. Businesses need to do the right things, such as investing in the initiatives that make the business better, surveys and presentations continually emphasize business and IT alignment, but what really should be talked about is sharing between business and IT: sharing the decision making in steering committees; sharing understanding and skills through co-operation and multi-disciplinary teams; and sharing responsibilities, risks and rewards.

2). Uncertainty must be accepted. This goes 'against the grain' of chief financial officers and other executives looking for hard numbers, but there are so many variables, including project costs, delivery time, customer behaviors and market assumptions, that mechanisms are needed to put organizations in a position to take timely corrective action. Only then will organizations dare to embark on initiatives that are uncertain but have the potential to result in huge returns, while at the same time be able to redirect or stop those that provide increasing indications of not delivering the expected benefits

3). IT governance is about completeness. The business case of IT projects needs to be complete, i.e., it needs to cover all the activities necessary to obtain the promised benefits - from inception of the idea to retirement of the service. The latter is already a big challenge requiring cultural changes because ongoing service delivery is rarely considered as part of a business case and the cost of taking an application out of service altogether is almost never considered. This relates to the second and third 'Ares', challenging whether the business has the right business and technology architecture and delivers against established quality standards.

4). IT governance is about accountability. If promises are made about the benefits that will be created by an IT enabled business initiative, someone needs to be accountable for those benefits. Accountability goes beyond delivering the IT services, because the ultimate benefits usually occur only as a result of associated business process changes. Whilst technical IT projects appeal to project leaders, few have the courage to step forward to lead projects that have a strong organizational and people impact. Nevertheless, there is significant evidence that such initiatives, whilst uncertain at the start, often have a major return on investment. Accountability not only applies when things go wrong, but also when rewards are apportioned upon success.

In order to obtain a general understanding of the processes which enable the IT governance structure, IT auditor should analyze relevant documents of the entity. IT strategies, plans and budgets-they provide evidence of planning and management s control of the IS environment and alignment with the business strategy, Security policy documentation Organization charts-the charts illustrate a division of responsibility and give an indication 
of the degree of segregation of duties within the organization, Job description-These descriptions define the functions and responsibilities of position throughout the organization. Furthermore, job descriptions give an indication of the degree of segregation of duties within the organization and may help identify possible conflicting duties, Steering committee reports-these reports provide documented information regarding new system projects, and Operations procedures-these procedures de-scribe the responsibilities of the operation staff. (Mirela Gheorghe, 2010).

From this point of view the developed audit strategy is a strategy based on risks to enable IT auditor to study from the best angle efficiency and effectiveness of the IT Governance structure. The evaluation of the risks associated with IT Governance is a key process in planning the audit mission which will allow the identification of the segments with increased risks (Hardy, 2009).

\section{The Study Reliability}

Cronbach Alpha has been computed by SPSS to identify the degree of internal consistency for the answers of the study sample, which was worth $74 \%$ which is higher than the standard percentage $60 \%$, and this means the possibility of relying on the findings and recommendations of the study, meaning that if another sample participated in answering the paragraphs of the questionnaire, the possibility of getting the same results will be $74 \%$.

\subsection{Demographic Variables}

Table 1 . Members of the study sample by educational qualification

\begin{tabular}{lcc}
\hline variable & frequency & percentage \\
\hline bachelor & 90 & \\
High diploma & 22 & \\
Master degree & 60 & \\
$\mathrm{PhD}$ & 19 & \\
Total & 191 & \\
\hline
\end{tabular}

We note from above table that most member of sample whose qualified with bachelor degree which indicate to reliability for results and recommendation for this study. master degree represent second most number in member of study and that another positive index to the study.

Table 2. Members of the study sample according to experience years

\begin{tabular}{lcc}
\hline variable & frequency & percentage \\
\hline Less than 6 years & 35 & \\
6-12 years & 58 & \\
13-18 years & 46 & \\
19 years and more & 42 & \\
total & 191 & \\
\hline
\end{tabular}

We note from above table that most members sample whose provided from 6-12 years experience, which mean member sample have adequate years experience to answer and understandable questionnaire paragraphs, and that positive index to reliability of conclusions of this study.

\subsection{Discuss the Hypotheses of the Study with Statistical Results}

The first hypothesis: Internal auditor does not deal commercial banks with regulations and instructions on information technology governance environment. 
Table 3. Arithmetic averages for the paragraphs that measure the regulations and instructions on information technology governance environment

\begin{tabular}{|c|c|c|c|}
\hline No. & Paragraph & Mean & Rank \\
\hline 1 & $\begin{array}{l}\text { Effective IT governance rules and regulations helps ensure that IT supports business goals, optimizes business } \\
\text { investment in IT, and appropriately manages IT-related risks and opportunities }\end{array}$ & 3.07 & 6 \\
\hline 2 & $\begin{array}{l}\text { An IT Governance audit evaluates an IT organization's strategic and operational alignment and rules and } \\
\text { regulation with its enterprise's business strategy, ensuring that IT is supporting the organization's overall goals }\end{array}$ & 4.23 & 2 \\
\hline 3 & $\begin{array}{l}\text { Auditing IT Governance needs more business knowledge than regular Information Systems (IS) audits because } \\
\text { the IS auditor has to evaluate how IT is enabling the business strategy for rules and regulations }\end{array}$ & 2.19 & 9 \\
\hline 4 & $\begin{array}{l}\text { Implicit in most governance legislation and regulation is the need for prudent governance of organizations IT } \\
\text { functions }\end{array}$ & 3.76 & 4 \\
\hline 5 & $\begin{array}{l}\text { As new laws and regulations are introduced to auditors to keep with their requirements challenge boards to } \\
\text { greater levels of transparency, objectivity and professionalism }\end{array}$ & 2.69 & 7 \\
\hline 6 & $\begin{array}{l}\text { Legal \& Regulatory Compliance is about Ensuring that your staff, policies and procedures are compliant with } \\
\text { legal and regulatory requirements }\end{array}$ & 4.49 & 1 \\
\hline 7 & $\begin{array}{l}\text { Auditors review the policies, procedures and activities that contribute to your controls. These can include } \\
\text { infrastructure configuration, change and patch management. }\end{array}$ & 3.16 & 5 \\
\hline 8 & Audit committee may assist the board in monitoring compliance with laws and regulations & 4.06 & 3 \\
\hline 9 & $\begin{array}{l}\text { Information technology (IT) auditors within internal audit departments are in a position to add great value to } \\
\text { their organizations during change rules and regulations }\end{array}$ & 2.17 & 8 \\
\hline Total & & 3.31 & 6 \\
\hline
\end{tabular}

We notes from above table that sixth paragraph has most acceptable by member of sample at average 4.49 which represent. Legal \& Regulatory Compliance is about Ensuring that your staff, policies and procedures are compliant with legal and regulatory requirements, which means internal policies cope with external rules and regulations and that good index according point view of internal auditors, and we note that second paragraph has next acceptable by average 4.23 which represents. An IT Governance audit evaluates an IT organization's strategic and operational alignment and rules and regulation with its enterprise's business strategy, ensuring that IT is supporting the organization's overall goals which means that rules and regulation cope with banks strategies.

$\mathrm{Bu}$ using IT Tools, and we note that eighth paragraph is third most acceptable by internal auditor by average 4.06 which represents Audit committee may assist the board in monitoring compliance with laws and regulations, which means that audit committee consider rules and regulation to monitoring banks activity. And we note third paragraph is less acceptable by internal auditors which represents Auditing IT Governance needs more business knowledge than regular Information Systems (IS) audits because the IS auditor has to evaluate how IT is enabling the business strategy for rules and regulations which mean must emphasize in future about information technology and its advantages to achieve goals of banks. as we note that average for first hypothesis is 3.31 and it more than supposed average and that means internal auditors in commercial banks accepted alternate hypothesis and reject the null hypothesis that Internal auditor deal commercial banks with regulations and instructions on information technology governance environment.

The second hypothesis: The auditor does not deal in commercial banks requirements ethics audit in the environment of the information technology governance.

Table 4. Arithmetic averages for the paragraphs that measure requirements ethics audit in the environment of the information technology governance

\begin{tabular}{|c|c|c|c|}
\hline No. & Paragraph & Mean & Rank \\
\hline 1 & $\begin{array}{l}\text { Auditors argues the need to promote ethical compliance in order for firms to achieve their IT governance } \\
\text { effectively }\end{array}$ & 4.61 & 1 \\
\hline 2 & Ethics has been perceived as one of the most important factors in establishing good corporate governance. & 3.11 & 7 \\
\hline 3 & $\begin{array}{l}\text { employees ethical and legal awareness increase, the employees tend to ask questions correctly and, in the end, } \\
\text { do "the right thing" when facing dilemmas }\end{array}$ & 2.08 & 8 \\
\hline 4 & $\begin{array}{l}\text { It is important for top management to lead in promoting awareness of ethical compliance within their } \\
\text { organization }\end{array}$ & 3.76 & 4 \\
\hline 5 & Auditor argues the need to promote a culture of ethical compliance in order for firms to achieve their IT & 4.03 & 3 \\
\hline
\end{tabular}




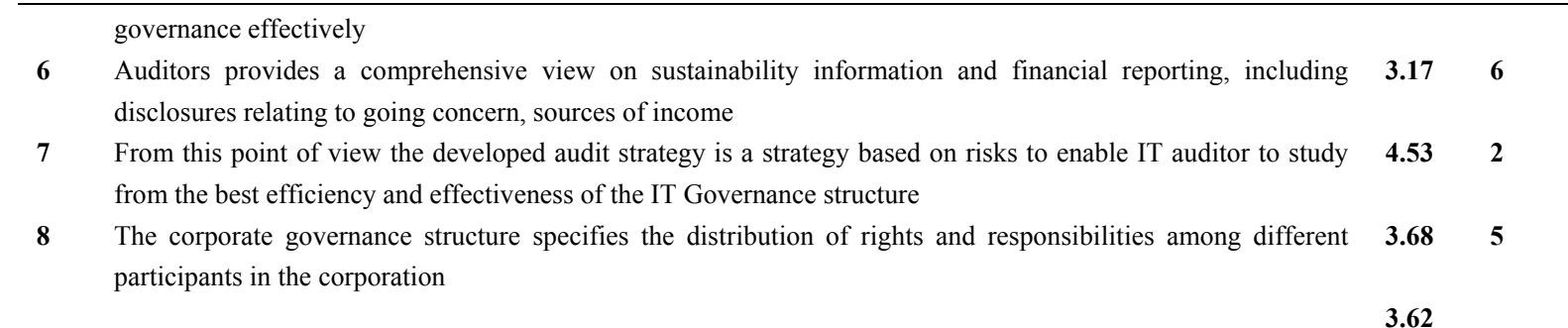

We note from above table that first paragraph is most acceptable by internal auditors which represents Auditors argues the need to promote ethical compliance in order for firms to achieve their IT governance effectively which means auditors play role in compliance with ethical requirements to cope with IT Governance, and we note that seventh paragraph is next most acceptable by internal auditors in commercial banks which represents From this point of view the developed audit strategy is a strategy based on risks to enable IT auditor to study from the best efficiency and effectiveness of the IT Governance structure which means IT Auditors promote tools to perform efficiency to cope with IT Governance, and we note that fifth paragraph is third acceptable by internal auditors which represents an Auditor argues the need to promote a culture of ethical compliance in order for firms to achieve their IT governance effectively.

And as we note average of hypothesis is 3.62 more than supposed average and that means internal auditors reject null hypothesis and accept alternate hypothesis that The auditor in commercial banks deal with requirements ethics audit in the environment of the information technology governance.

\section{Results and Recommendation}

\subsection{Results}

1)-Legal \& Regulatory Compliance is about Ensuring that your staff, policies and procedures are compliant with legal and regulatory requirements.

2)-IT Governance audit evaluates an IT organization's strategic and operational alignment and rules and regulation with its enterprise's business strategy, ensuring that IT is supporting the organization's overall goals.

3)-Implicit in most governance legislation and regulation is the need for prudent governance of organizations IT functions.

4)-Auditors review the policies, procedures and activities that contribute to your controls. These can include infrastructure configuration, change and patch management.

5)-Auditors argues the need to promote ethical compliance in order for firms to achieve their IT governance effectively.

6)-Audit strategy is a strategy based on risks to enable IT auditor to study from the best efficiency and effectiveness of the IT Governance structure.

7)-Auditor argues the need to promote a culture of ethical compliance in order for firms to achieve their IT governance effectively.

8)-It is important for top management to lead in promoting awareness of ethical compliance within their organization.

\subsection{Recommendations}

1)-its important to care Auditing IT Governance needs more business knowledge than regular Information Systems (IS) audits because the IS auditor has to evaluate how IT is enabling the business strategy for rules and regulations.

2)-its important to care Information technology (IT) auditors within internal audit departments are in a position to add great value to their organizations during change rules and regulations.

3)-Its important to care as new laws and regulations are introduced to auditors to keep with their requirements challenge boards to greater levels of transparency, objectivity and professionalism.

4)-Effective IT governance rules and regulations helps ensure that IT supports business goals, optimizes business investment in IT, and appropriately manages IT-related risks and opportunities.

5)-Employees ethical and legal awareness increase, the employees tend to ask questions correctly and, in the end, 
do "the right thing" when facing dilemmas.

6)-Ethics has been perceived as one of the most important factors in establishing good corporate governance.

\section{References}

Al-Hosban, A. (2014). Impact of conditional factors on internal control system in keeping with the requirements of information technology from the point of view of ICT auditors at commercial banks in Jordan. International Journal of Economics and Finance. http://dx.doi.org/10.5539/ijef.v6n11p245

Arjoon, S., \& Gopaul, J. (2003). Ethical Orientation of Future Managers: The Case of Trinidad. Social and Economic Studies, 52(1), 99-117.

Coffin, B. (2003). Ethics and Compliance at Honda of America. Risk Management, 50(12).

De Prada, V. (2002). The Founder of Opus Dei: The Life of Josemaria Escriva Volume II: Daring. New York: Scepter.

El Sawy, O. A., \& Pavlou, P. A. (2008). IT-Enabled Business Capabilities for Turbulent Environments. MIS Quarterly Executive, 7(3), 139-150.

Erik, G. (2007). The Rule of Four of IT Governance. Systems Control Journal, 6.

Farrell, J. (2014). Governance and compliance. KPMG International Cooperative.

Green, P. (2009). The role of culture of compliance in IT Governance, proceeding GRCIS.

Haes, S. D., \& Grembergen, W. V. (2004). IT Governance and Its Mechanisms. Information Systems Control Journal, 1.

Hardy, G. (2009). The Role of the IT Auditor in IT Governance. Information Systems Control Journal.

Harshbarger, S., \& Holden, T. (2004). The New Realities of Corporate Governance. Ethics Matters, February, Center for Business Ethics, Bentley College, MA.

Information Systems Audit and Control As-sociation. (2009). CISA Review Manual.

Information Systems Audit and Control Association. (2009). Is auditing guideline, use of risk assessment in audit planning risks. IT Governance Institute, Board Briefing on IT Governance (pp. 11-14).

IT Assurance Frame Work. (2011). ISACA.

Jacobs, J. (2004). Corporate Governance Reform: What It Means for Associations. Association Management, $56(1), 17$.

Jill, J. D. (2014). Auditor Ethics for Continuous Auditing and Continuous Monitoring. ISACA.

Mehai, F. (n.d.). Auditing IT Governance. Information Economical, 14(1), 39.

Meyer, N. D. (2004). Systemic IS Governance: An Introduction. Information Systems Management, 21(4), 2334. http://dx.doi.org/10.1201/1078/44705.21.4.20040901/84184.3

Mirela, G. (2010). Audit Methodology for IT Governance. Informatica Economică, 14(1), 32.

Parent, M., \& Reich, B. H. (2009). Governing IT Risk. California Management Review. http://dx.doi.org/10.2307/41166497

Robert, M. (2013). Executive's Guide to IT Governance: Improving Systems Processes with Service Management, COBIT, and ITIL.

Trevino, L. K., Weaver, G. R., Gibson, D. G., \& Toffler, B. L. (1999). Managing Ethics and Legal Compliance: What Works and What Hurts. California Management Review, 41(2), 131-151. http://dx.doi.org/10.2307/41165990

Vaswani, R. (2003). Determinants of Effective Information Technology (IT) Governance. Unpublished Thesis. School of Business, University of Queensland, Australia.

\section{Copyrights}

Copyright for this article is retained by the author(s), with first publication rights granted to the journal.

This is an open-access article distributed under the terms and conditions of the Creative Commons Attribution license (http://creativecommons.org/licenses/by/3.0/). 